\title{
Applying social cognitive theory to predict physical activity and dietary behavior among patients with type-2 diabetes
}

\author{
Ann Tresa Sebastian ${ }^{1}$, Eslavath Rajkumar ${ }^{1}{ }^{a}, \mathrm{P}$ Tejaswini ${ }^{2}, \mathrm{R}_{\text {Lakshmi }}{ }^{\text {, J }}$ Romate ${ }^{1}$ \\ ${ }^{1}$ Department of Psychology, Central University of Karnataka, ${ }^{2}$ Department of Psychology, Jyothinivas College \\ Keywords: dietary behaviour, physical activity, type-2 diabetes, social cognitive theory \\ https://doi.org/10.52965/001c.24510
}

\section{Health Psychology Research}

Vol. 9, Issue 1, 2021

\section{Introduction}

Non-communicable diseases, arising out of changing lifestyle habits of people, are the foremost causes of mortality and morbidity worldwide. Most of these diseases occur in low and middle-income countries. Chronic diseases can be managed with the help of health behaviors such as proper diet, physical exercise, adherence to medication, and avoidance of health risk behaviors such as smoking, alcohol consumption, sedentary lifestyle, etc. The social cognitive theory addresses the role of personal and environmental factors in an individual's health behavior. The current study aims to understand the role of social cognitive theory on physical activity and dietary behavior amongst individuals diagnosed with type-2 diabetes.

\section{Methods}

A correlational study was conducted among 225 participants with type-2 diabetes, who are under medication. The data was collected using social cognitive questionnaire for physical activity \& dietary behavior and Health-Promoting Lifestyle Profile II. Descriptive statistics, Pearson's correlation coefficient and multiple linear regression analysis were used to analyze the data.

\section{Results}

It was found from the study results that, all the domains of social cognitive theory were significantly correlated with physical activity $(\mathrm{p}<0.001)$ and the SCT domainsself-regulation $(p<0.001)$, social support $(p<0.001)$, and outcome expectancy $(p<0.05)$ were significantly correlated with dietary behavior. The results of multiple linear regressions indicated that the domains self- regulation and self- efficacy were the significant predictor for physical activity behavior $\left(\mathrm{R}^{2}=.21, \mathrm{p} \leqslant 0.001\right)$ while the domains social support and self-regulation were the significant predictor of dietary behavior $\left(\mathrm{R}^{2}=.09\right.$, $\mathrm{p} \leqslant 0.001)$.

\section{Conclusion}

The study results show that there is an influence of social cognitive domains on physical activity and dietary behaviour. Further, this study suggests that social cognitive theory based intervention can be used to promote healthy behaviour.

\section{INTRODUCTION}

A healthy lifestyle of an individual is a combination of multiple factors like adequate physical activity, healthy and nutritious diet, and avoiding health risk behaviors like con- sumption of alcohol and smoking. ${ }^{1}$ An unhealthy diet contributes to metabolic syndrome, a cluster of health issues including hypertension, abdominal obesity, and improper insulin metabolism, which increases the risk of developing Non-communicable diseases. ${ }^{2}$ Literature has

\footnotetext{
a Corresponding author:

Eslavath Rajkumar

Department of Psychology,

Central University of Karnataka.

E-mail: rajkumare@cuk.ac.in
} 
reported that engaging in a low-risk lifestyle affects a lower risk of chronic diseases such as coronary heart disease and diabetes. ${ }^{3}$ However, with the increase in a sedentary lifestyle, there is an increasing risk of non-communicable diseases (NCD) such as hypertension, cardiovascular diseases, and respiratory problems.

NCD's are considered to be the foremost cause of premature deaths all around the world. According to the World Health Organization, ${ }^{4}$ nearly 41 million deaths every year are accounted to non-communicable diseases, which is equal to $71 \%$ of the deaths worldwide. Almost $75 \%$ of all deaths occur in low and middle-income countries, most of the people dying before the age of 70 . Literature indicates that the modifiable risk factors are set up during adolescence, and these set the stage for NCDs in adulthood which is due to the time between the exposure to risk factors and the development of diseases. ${ }^{5-7}$ Lack of physical activity and unhealthy diet people consume are identified as the most critical risk factors of non-communicable diseases.

Sigal et al., 8 in their study, have reported that following healthy dietary habits and an adequate amount of physical activity are considered to be the keystone in management among patients diagnosed with diabetes mellitus and also in the etiology as well as treatment for most of the noncommunicable diseases. ${ }^{9}$ Despite understanding the importance of changes required to lead a healthy life, people fail to follow them. Studies reveal that $50 \%$ of the population engaging in physical activities tend to drop out from such programs, highlighting the need for health behavior change interventions to tackle such issues that can be a part of the standard health care practices. ${ }^{10,11}$ This brings the question of why dropouts occur and what can be done to get an individual back to a healthy lifestyle. It has to be understood that adherence to physical activity is a combination of various factors such as social, emotional, and environmental factors that need to be looked into by healthcare professionals (Et al., 2018). Researchers have developed different theories and models to understand why individuals engage in health behaviors. ${ }^{12}$ Theories such as the health belief model, ${ }^{13,14}$ stages of change model, the theory of reasoned action, ${ }^{15}$ protection motivation, ${ }^{16}$ social cognitive theory, ${ }^{17,18}$ etc. have attempted to explain health behavior and to guide the identification, development, and implementation of interventions. ${ }^{19}$

Amongst the theories mentioned above, the social cognitive theory addresses the role of socio-structural as well as the personal determinants of health behaviors. ${ }^{20}$ The social cognitive theory explains human behavior using a threeway model in which environment, personal factors, and behavior interact continuously. ${ }^{21}$ In other words, the focus of this theoretical framework is on how the individual's personal experience, actions and experiences of others and the influence of the environmental factors on the health behavior of the individual, thus giving it a name 'triadic reciprocal causation. ${ }^{22}$ "Social cognitive theory, in its totality, specifies factors governing the acquisition of competencies that can profoundly affect physical and emotional well-being as well as the self-regulation of health habits." 23 The theory has a incredible influence on the planning and compliance of health behaviors such as physical activity and dietary behavior. Selfefficacy is the personal belief that a task can be successfully achieved. The concept of SCT was introduced by Bandura ${ }^{24}$ to acknowledge the role of cognitive factors in motivating and enabling people to act and alter their behaviors. ${ }^{22}$ Selfefficacy is the personal belief that a task can be successfully achieved. Self-regulation is the management of one's behavior with the help of planning, setting goals, and selfmonitoring to control their behavior. ${ }^{25}$ Social support is the assistance individuals get when they are performing a behavior. Outcome expectancies are understood as the positive or negative beliefs people hold towards behavior outcomes. $^{26}$

Stacey et al. ${ }^{27}$ have reported that social cognitive interventions have a significant effect on physical activity and the SCT interventions give a promising improvement in the individuals, and this is found to be effective in studies on pre-diabetic individuals. ${ }^{21,28}$ Apart from physical interventions, the computer-based SCT interventions also promote dietary changes and behavioral changes amongst youth. ${ }^{29}$ Literature also reported that SCT had increased dietary selfefficacy among individuals. ${ }^{30,31}$ Community-based interventions with SCT also impacted knowledge, health behavior, and other self-report behavior. ${ }^{32}$ By considering the importance of SCT in managing and controlling health risk behaviors, the present study tried to understand the influence on physical activity and dietary behavior among participants with type-2 diabetes as they require a lot of behavior change.

\section{METHODS}

\section{STUDY DESIGN}

The present cross-sectional study used correlational research design to investigate the influence of domains of social cognitive theory on physical activity and dietary behavior among individuals diagnosed with type 2 diabetes.

\section{PARTICIPANTS}

The target population for the present study was individuals diagnosed with type 2 diabetes. A purposive sampling method was employed to recruit 225 participants from Kerala, South India, with inclusion criteria who are taking medication for type- 2 diabetes mellitus.

\section{TOOLS USED}

The SCT questionnaire developed by Nematollahi \& Eslami. ${ }^{33}$ It was used to collect the data related to physical activity and dietary behaviour concerning social cognitive domains. The scale had 20 questions and four sub domains: self-efficacy, self-regulation, social support, and outcome expectancy. The responses in the Likert scale were; not at all $=1$, little $=2$, somewhat $=3$, fairly $=4$, and completely $=5$. For the PAQ-SCT, the Cronbach's alpha was .91 and the Cronbach's alpha of the scale adopted for SAT dietary behavior was .83 .

Health-promoting lifestyle profile -II (HPLP-II) was used to analyze the diet and physical exercise of the participants. It consists of 52 items and has six subscales, including health responsibility, spiritual growth, physical activity, interpersonal relation, nutrition, and stress management. 
Table 1. Sample characteristics

\begin{tabular}{ccccccc}
\hline Variables & & N & \% & M & SD & Range \\
\hline Age & & & & 51.94 & 14.53 & $19-89$ \\
Gender & Male & 104 & 46.22 & & \\
& Female & 121 & 53.77 & & \\
Residence & Urban & 100 & 44.44 & & \\
& Rural & 125 & 55.55 & & \\
& & & &
\end{tabular}

Table 2. Correlations between the domains of social cognitive theory and physical activity $(\mathrm{N}=225)$

\begin{tabular}{|c|c|c|c|c|c|}
\hline Variables study & $\begin{array}{l}\text { Physical } \\
\text { Activity }\end{array}$ & $\begin{array}{c}\text { Self- } \\
\text { Efficacy }\end{array}$ & $\begin{array}{c}\text { Self- } \\
\text { Regulation }\end{array}$ & $\begin{array}{c}\text { Social } \\
\text { Support }\end{array}$ & $\begin{array}{l}\text { Outcome } \\
\text { Expectancy }\end{array}$ \\
\hline Physical Activity & 1 & & & & \\
\hline Self-Efficacy & $.41^{* *}$ & 1 & & & \\
\hline Self-Regulation & $.44^{* *}$ & $.68^{* *}$ & 1 & & \\
\hline Social Support & $.35^{* *}$ & $.57^{* *}$ & $.66^{* *}$ & 1 & \\
\hline $\begin{array}{l}\text { Outcome } \\
\text { Expectancy }\end{array}$ & $.33^{* *}$ & $.47^{* *}$ & $.50^{* *}$ & $.50^{* *}$ & 1 \\
\hline
\end{tabular}

${ }^{*} p<0.05 ; * * p<0.001$

The tool is a four-point Likert scale with scores ranging from never $=1$, sometimes $=2$, frequently $=3$ to regularly $=$ 4. The total scores ranged from 52 to $208^{35}$ For the present study, the Cronbach's alpha was 0.82 . There are 8 items under the domain, physical activity and 9 items under the domain, nutrition, were used for the present study.

\section{DATA COLLECTION}

The researcher approached two different primary health care centers. The participants were debriefed about the purpose of the study, participation in the study was voluntary, and those who volunteered were asked to sign a written consent form. Initially, the blood glucose level of the participants was taken using a blood glucose meter, and later selfadministered questionnaires regarding the determinants of social cognitive theory on physical activity and dietary behavior were given to fill. Once the participants completed the responses, the questionnaire was collected back, and any information that showed the participant's identity was removed to maintain anonymity and confidentiality.

\section{STATISTICAL ANALYSIS}

The data were analyzed using IBM SPSS (Version 20). Descriptive statistics were used to see sample characteristics. Pearson correlation coefficient was used to see the relationship between study variables. Multiple linear regressions were used to investigate the influence of social cognitive domains on physical activity and dietary behavior.

\section{RESULTS}

Table 1 shows the sample characteristic. The sample consisted of 225 diabetic patients. The mean age of participants was 51.94 years $(\mathrm{SD}=14.53)$. Among 225 participants, 121 were females and 104 males. One hundred participants were from urban, and 125 were from rural backgrounds. Table 2 shows the Pearson correlation coefficient analysis between the domains of social cognitive theory and physical activity among the participants. The variables self-efficacy $(r=.41)$, self-regulation $(\mathrm{r}=.44)$, social support (.35), and outcome expectancy $(r=.33)$ domains of socialcognitive theory had shown a significant and positive correlation with physical activity at $\mathrm{p}<0.001$ levels.

Table 3 shows the multiple regression analysis of four domains of SCT as predictor of physical activity. A significant influence of domains of social cognitive theory on physical activity is positively significant at $\mathrm{p}<0.001$ evel. The initial model shows a total variance of $19.4 \%$, while the latter model shows a $21.8 \%$ variance of independent variables Self- regulation and self-efficacy on physical activity. The initial step could only load self-regulation in the model significantly as a positive predictor of Physical Activity at $\mathrm{p}<0.00$ level. In comparison, the second step could once again load self-regulation as a positive predictor of physical activity and self-efficacy in the model at $\mathrm{p}<0.000$ and $\mathrm{p}<0.05$ levels, respectively.

Table 4 shows the Pearson correlation coefficient analysis between SCT domains and dietary behavior among the participants. The variable sociocognitive theory domains of self-regulation( $\mathrm{r}=.20, \mathrm{p}<0.001)$, social $\operatorname{support}(\mathrm{r}=.29$, $\mathrm{p}<0.001)$, and outcome expectancy $(\mathrm{r}=.16, \mathrm{p}<0.05)$ were sig- 
Table 3. Stepwise multiple linear regression analysis for the domains of social cognitive theory as predictor of physical activity.

\begin{tabular}{|c|c|c|c|c|c|}
\hline Variables & $\begin{array}{l}\text { Model } 1 \\
\operatorname{Std} \beta\end{array}$ & $t$ & $\begin{array}{c}\text { Model } 2 \\
\operatorname{Std} \beta\end{array}$ & & $t$ \\
\hline Self- Regulation & .44 & $7.32^{* * *}$ & .29 & & $3.60^{* * *}$ \\
\hline Self-Efficacy & & & .21 & & $2.58^{*}$ \\
\hline $\mathrm{R}$ & \multicolumn{2}{|c|}{.44} & \multicolumn{3}{|c|}{.46} \\
\hline $\mathrm{R}^{2}$ & \multicolumn{2}{|c|}{.19} & \multicolumn{3}{|c|}{.21} \\
\hline $\mathrm{F}$ & \multicolumn{2}{|c|}{$53.70^{* * *}$} & \multicolumn{3}{|c|}{$30.89^{* * *}$} \\
\hline$\Delta \mathrm{R}^{2}$ & \multicolumn{2}{|c|}{.19} & \multicolumn{3}{|c|}{.21} \\
\hline$\Delta \mathrm{F}$ & \multicolumn{2}{|c|}{53.70} & \multicolumn{3}{|c|}{6.70} \\
\hline
\end{tabular}

${ }^{*} p<0.05 ; * * * p<0.001 ; * * * * p \leqslant 0.001$

Table 4. Correlations between the four domains of social cognitive theory and dietary behavior. $(\mathrm{N}=225)$

\begin{tabular}{|c|c|c|c|c|c|}
\hline Variables study & $\begin{array}{l}\text { Dietary } \\
\text { Behaviour }\end{array}$ & $\begin{array}{c}\text { Self- } \\
\text { Efficacy }\end{array}$ & $\begin{array}{c}\text { Self- } \\
\text { Regulation }\end{array}$ & $\begin{array}{l}\text { Social } \\
\text { Support }\end{array}$ & $\begin{array}{c}\text { Outcome } \\
\text { Expectancy }\end{array}$ \\
\hline Dietary Behaviour & 1 & & & & \\
\hline Self-Efficacy & .06 & 1 & & & \\
\hline Self-Regulation & $.20^{* *}$ & $.46^{* *}$ & 1 & & \\
\hline Social Support & $.29^{* *}$ & .09 & $.28^{* *}$ & 1 & \\
\hline $\begin{array}{c}\text { Outcome } \\
\text { Expectancy }\end{array}$ & $.16^{*}$ & .06 & $.37^{* *}$ & $.51^{* *}$ & 1 \\
\hline
\end{tabular}

$* p<0.05 ; * * p<0.001$

Table 5. Stepwise multiple linear regression analysis for the four domains of social cognitive theory as predictor of dietary behavior.

\begin{tabular}{|c|c|c|c|c|}
\hline Variables & $\begin{array}{c}\text { Model } 1 \\
\operatorname{Std} \beta\end{array}$ & $\mathrm{t}$ & $\begin{array}{c}\text { Model } 2 \\
\operatorname{Std} \beta\end{array}$ & $t$ \\
\hline Social Support & .29 & $4.68^{* * *}$ & .26 & $3.93^{* * *}$ \\
\hline Self- Regulation & & & .13 & $2.01^{*}$ \\
\hline $\mathrm{R}$ & \multicolumn{2}{|c|}{.29} & \multicolumn{2}{|c|}{.32} \\
\hline$R^{2}$ & \multicolumn{2}{|c|}{.09} & \multicolumn{2}{|c|}{.10} \\
\hline$F$ & \multicolumn{2}{|c|}{$21.92^{* * *}$} & \multicolumn{2}{|c|}{$13.13^{* * *}$} \\
\hline$\Delta \mathrm{R}^{2}$ & \multicolumn{2}{|c|}{.08} & \multicolumn{2}{|c|}{.09} \\
\hline$\Delta \mathrm{F}$ & \multicolumn{2}{|c|}{21.92} & \multicolumn{2}{|c|}{4.04} \\
\hline
\end{tabular}

${ }^{*} p<0.05 ; * *{ }^{* *} p<0.001 ; * * * * 0 \leqslant 0.001$

nificantly correlated with dietary behavior, while the analysis has shown no significant relationship between self-efficacy and dietary behavior.

Table 5 shows the multiple regression analysis: The SCT domains as predictor of dietary behavior. A significant influence of domains of social cognitive theory on dietary behavior is positively significant at $\mathrm{p} \leqslant 0.001$ level. The initial model showed a total variance of $9 \%$, while the latter model showed $10.6 \%$ of the variance of independent variables, i.e., social support and self-regulation on dietary behavior. The initial step could only load social support in the model significantly as a positive predictor of dietary behavior at $p \leqslant 0.001$ level while the second step could once again load self-regulation as a positive predictor of dietary behavior along with social support in the model at $p \leqslant 0.001$ and $\mathrm{p}<0.05$ level respectively 


\section{DISCUSSION}

Social cognitive theory by Albert Bandura emphasizes the interaction of the social, environmental, and personal factors that influence individuals' health behaviors. The present study aimed at understanding the influence of SCT theory on physical activity and dietary behavior of patients diagnosed with diabetes and undergoing medication for the same. The study results show that social cognitive theory has a positive impact on the physical activity of diabetic patients. Studies have shown that there is a positive impact on social cognitive theory on physical exercise. A meta-analysis and systematic review of forty-four articles by Young et al. ${ }^{36}$ showed that self-efficacy and goals were associated with physical activity and outcome expectations, and sociocultural factors did not influence individuals' physical activity. Stacey et al. ${ }^{27}$ have also highlighted that SCT-based interventions help improve physical activity and diet behaviors among cancer survivors. Shamizadeh et al., ${ }^{21}$ through their SCT-based physical activity intervention on pre-diabetics, also highlight the effectiveness to reduce the risk of pre-diabetes developing into diabetes.

Self-efficacy is the personal belief that a task can be successfully achieved. The concept was introduced by Bandura $^{24}$ to acknowledge the role of cognitive factors in motivating and enabling people to act and alter their behaviors. $^{22}$ Self-efficacy and physical activity are found to have a significant positive correlation in the present study. Oyibo et al. ${ }^{26}$ found that the perceived self-efficacy of an individual strongly predicts bodyweight exercises. Self-efficacy also has a direct effect on the exercise behavior of men. In a study on the STC and physical activity among Korean male high-school students, it was found that self-efficacy indirectly affects physical activity behavior which can be seen through goal setting and perceived benefits. ${ }^{37}$ Ghoreishi et al., 38 in their intervention study on self-care behaviors among people with type 2 diabetes, indicated that with intervention, the self-efficacy to overcome barriers played a role in the management of diabetes. Shamizadeh et al., ${ }^{21}$ through their SCT-based physical activity intervention on the pre-diabetics study, reported that, with the increase in self-efficacy, had a significant reduction in blood sugar levels and BMI and were leading healthier lifestyles. The significant positive correlation of self-efficacy and physical activity of the patients in the present study could be due to the belief that physical activity can help manage their diabetes. This increases the motivation of the patients to alter their lifestyle, which could help control their blood sugar levels better.

Self-regulation is found to have a significant positive correlation with physical activity. Self-regulation is the management of one's behavior with the help of planning, setting goals, and self-monitoring to control their behavior. ${ }^{25}$ It is defined as "a set of psychological and perceptual processes by which individuals work toward achieving goals and objectives by keeping them on track and minimizing distractions or impulses." 25 Anderson et al. ${ }^{39}$ reported that self-regulation has a powerful influence on physical activity. Still, contrastingly Oiybo et al. ${ }^{26}$ have found that selfregulation did not impact exercise. Umstattd ${ }^{40}$ found that using self-regulation strategies has better reporting of their health and better engagement with physical activity. The positive correlation between self-regulation and physical activity indicates that with proper planning and goal setting, the participants can engage in physical activity that, in turn, helps manage their diabetes.

Social support is the assistance individuals get when they are performing a behavior. Physical activity and social support have a positive correlation in this study. This might be because the immediate social support that the patient possesses will be providing a motivating and encouraging environment, which might be keeping the patient engage inadequate physical exercise, which is required. Plotnikoff et al. ${ }^{41}$ found that social support had a high correlation with physical activity. They highlighted that both social support and outcome expectancies are responsible for improving goal setting and physical activity. Oiybo et al. ${ }^{26}$ have identified social support as a powerful determinant of the exercise behavior of individuals, specifically women.

Outcome expectancy and physical activity have a significant positive relationship. Outcome expectancies are understood as the positive or negative beliefs people hold towards behavior outcomes. ${ }^{26}$ Williams et al. ${ }^{35}$ showed how outcome expectancy has a mixed result with positive effects predicting physical activity among older adults, and adverse outcomes result from personal barriers. For the present study, the results came with a significant positive relationship with the outcome expectancy and physical exercise, maybe because the patients might have understood that engaging in healthy regimes like engaging inadequate physical exercise can significantly bring the health condition much better. These activities may evidentially add for better health of oneself.

Social cognitive theory domains are also found to influence the diet of individuals in the present study positively. In a survey of the community-based diabetes education program, using SCT and stages of change theory in interventions showed that post-intervention has a positive impact on knowledge, health beliefs, and self-reported behaviors can help people with diabetes to act and change their diet and prepare meals that were healthy. ${ }^{32}$ A study by Mehta et al. ${ }^{42}$ showed that SCT constructs did not have any relationship with the dietary behaviors, which was assessed by the number of portions of fruit and vegetable consumption.

In the present study, self-efficacy did not have a relationship with diet. In a survey by Doerksen and McAuley, ${ }^{43}$ it was seen that in the dietary behaviors of university employees, self-efficacy significantly predicted low-fat consumption. Through their study, Beverly et al. ${ }^{44}$ state that high self-efficacy was related to healthy food habits, and low self-efficacy was related to unhealthy habits. Rolling and Hong ${ }^{45}$ showed that high self-efficacy showed lower consumption of unhealthy food such as sugar and fat and higher consumption of fruits and vegetables. It is evident from the studies that healthy food consumption was correlated with high-self efficacy. In the present study, the weak correlation between self-efficacy and diet shows that while self-efficacy plays a role in the dietary behaviors of diabetics, it does not have a strong influence. This could be because, despite the motivation to change the nutritional behaviors, other factors such as social support, availability of the diet, and the reluctance to change dietary patterns may 
play a role.

Self-regulation is found to have a significant correlation with diet in the present study. Torkan et al. ${ }^{46}$ found that self-regulation has a substantial relationship with the dietary habits of pregnant women in the avoidance of unhealthy food. In a study by Bill et al., ${ }^{47}$ it was found that self-regulation played a significant role in healthier food choices among individuals. Self-regulation and social support predicted nutrition behavior among web users. The positive correlation of self-regulation with diet could be because diabetes patients could have a goal to engage in healthy dietary habits to manage their diabetes by maintaining their blood sugar levels.

Social support and dietary behavior have a significant positive relationship in this study. In the study by Beverly et al., ${ }^{44}$ social support was higher among boys than girls to consume healthy food. Anderson et al. ${ }^{39}$ have identified that social support and self-regulation contributed to the nutrition behavior of adults. The social support that the individual has might encourage them to take up healthy dietary habits and might be supporting them to continue the healthy regime, which might have led to the positive relationship that the results show.

Outcome expectancy and dietary behavior have a significant positive relationship. Doerksen and McAuley ${ }^{43}$ identified that outcome expectancies predicted fruit and vegetable consumption among university employees. Negative outcome expectations had a positive influence on the nutrition behavior of adults. ${ }^{39}$ Torkan et al. ${ }^{46}$ found that pos- itive outcome expectations from the diet were significantly related to nutrition behavior. Sheeshka et al. ${ }^{48}$ found that outcome expectancies did not help predict the intention to practice healthy eating behaviors. Doerksen and McAuley 43 reported that outcome expectancies predicted fruit and vegetable consumption and low-fat food consumption. The results obtained in the study the diabetic patients might have a positive belief that engaging in taking a healthy diet can reduce or maintain their current condition, which is also evident from the literature.

\section{CONCLUSION}

The present study results show that social cognitive theory domains impact the physical activity and dietary behaviors of patients with diabetes undergoing medication. The results indicate that patients who had set goals and constantly monitored themselves had the self-efficacy to engage in behaviors to manage their diabetes by including physical activities and changing their dietary behavior. Social support, in the form of help from family and friends ensured that the health behaviors were taken up and managed over time. So, in the future, studies could take the SCT model as an intervention framework to understand the effect on physical activity and dietary behavior.

Submitted: September 17, 2020 EST, Accepted: November 10, 2020 EST 


\section{REFERENCES}

1. Chiuve SE, Rexrode KM, Spiegelman D, Logroscino G, Manson JE, Rimm EB. Primary prevention of stroke by a healthy lifestyle. Circulation.

2008;118(9):947-954. doi:10.1161/circulationaha.10 $\underline{8.781062}$

2. Olatona FA, Onabanjo OO, Ugbaja RN, Nnoaham KE, Adelekan DA. Dietary habits and metabolic risk factors for non-communicable diseases in a university undergraduate population. J Health Popul Nutr. 2018;37(1):21. doi:10.1186/s41043-018-0152-2

3. McCullough ML, Feskanich D, Stampfer MJ, et al. Diet quality and major chronic disease risk in men and women: Moving toward improved dietary guidance. The American journal of clinical nutrition. 2002;76(6):1261-1271. doi:10.1093/ajcn/76.6.1261

4. World Health Organization. Non-communicable diseases. Fact sheets. World Health Organization; 2018. https://www.who.int/news-room/fact-sheets/de tail/non-communicable-diseases

5. Selvan MS, Kurpad AV. Primary prevention: Why focus on children \& young adolescents? Indian Journal of Medical Research. 2004;120(6):511-518. htt ps://www.researchgate.net/profile/Mano_Selvan/publ ication/8077552_Primary_prevention_Why focus 0 n_children_young_adolescents/links/56b0b74308ae9f 0ff7b7530a/Primary-prevention-Why-focus-on-childr en-young-adolescents.pdf

6. Naik R, Kaneda T. Non-communicable diseases in Africa: youth are key to curbing the epidemic and achieving sustainable development. Policy brief. Population bureau; 2015. https://assets.prb.org/pdf1 5/ncds-africa-policybrief.pdf

7. Gamage AU, Jayawardana PL. Knowledge of noncommunicable diseases and practices related to healthy lifestyles among adolescents, in state schools of a selected educational division in Sri Lanka. BMC Public Health. 2017;18(1):64. doi:10.1186/s12889-01 $\underline{7-4622-\mathrm{Z}}$

8. Sigal RJ, Kenny GP, Wasserman DH, CastanedaSceppa C. Physical activity/exercise and type 2 diabetes. Diabetes Care. 2004;27(10):2518-2539. doi:1 $\underline{0.2337 / \text { diacare.27.10.2518 }}$

9. Little P, Margetts B. The importance of diet and physical activity in the treatment of conditions managed in general practice. British Journal of General Practice. 1996;46(404):187-192.
10. Dishman RK. Predicting and changing exercise and physical activity: what's practical and what's not. Toward active living. Published online 1994:97-106.

11. Kelly MP, Barker M. Why is changing healthrelated behaviour so difficult? Public Health. 2016;136:109-116. doi:10.1016/j.puhe.2016.03.030

12. Rejeski WJ, Fanning J. Models and theories of health behavior and clinical interventions in aging: A contemporary, integrative approach. Clinical interventions in aging. 2019;14:1007-1019. doi:10.214 7/cia.s206974

13. Becker MH, ed. The Health Belief Model and Personal Health Behavior. Health Education Monographs. 1974;2(4):324-473. doi:10.1177/1090198 $\underline{17400200407}$

14. Rosenstock IM. The health belief model and preventive health behavior. Health Education Monographs. 1974;2(4):354-386. doi:10.1177/1090198 17400200405

15. Ajzen I, Fishbein M. Understanding Attitudes and Predicting Social Behavior. Prentice-Hall; 1980.

16. Rogers RW. Cognitive and physiological processes in fear appeals and attitude change: A revised theory of protection motivation. In: Cacioppo JT, Petty RE, eds. Social Psychophysiology. Guilford Press; 1983:153-176.

17. Bandura A. Social Foundations of Thought and Action: A Social Cognitive Theory. Prentice-Hall; 1986.

18. Bandura A. Self-Efficacy: The Exercise of Control. Freeman; 1997.

19. Albarracín D, Johnson BT, Fishbein M, Muellerleile PA. Theories of reasoned action and planned behavior as models of condom use: A metaanalysis. Psychological Bulletin. 2001;127(1):142-161. doi:10.1037/0033-2909.127.1.142

20. Bandura A. Health promotion from the perspective of social cognitive theory. In: Norman P, Abraham C, Conner M, eds. Understanding and Changing Behavior: From Health Beliefs to SelfRegulation. Harwood Academic; 2000.

21. Shamizadeh T, Jahangiry L, Sarbakhsh P, Ponnet K. Social cognitive theory-based intervention to promote physical activity among prediabetic rural people: A cluster randomized controlled trial. Trials. 2019;20(1):98. doi:10.1186/s13063-019-3220-Z 
22. Jenkins L, Hall H, Raeside R. Applications and applicability of Social Cognitive Theory in Information Science Research. Journal of Librarianship and Information Science. Published online 2018. http s://www.napier.ac.uk/ /media/worktribe/output-1017 697/applications-and-applicability-of-social-cognitiv e-theory-in-information-science-research-2.pdf

23. Bandura A. Health promotion from the perspective of social cognitive theory. Psychology \& Health. 1998;13(4):623-649. doi:10.1080/0887044980 $\underline{8407422}$

24. Bandura A. Self-efficacy: Toward a unifying theory of behavioral change. Psychological Review. 1977;84(2):191-215. doi:10.1037/0033-295x.84.2.191

25. Castonguay A, Miquelon P, Boudreau F. Selfregulation resources and physical activity participation among adults with type 2 diabetes. Health Psychology Open. 2018;5(1):205510291775033. doi:10.1177/2055102917750331

26. Oyibo K, Adaji I, Vassileva J. Social cognitive determinants of exercise behavior in the context of behavior modeling: A mixed-method approach. Digital health. 2018;4:2055207618811555. doi:10.117 $\underline{7 / 2055207618811555}$

27. Stacey FG, James EL, Chapman K, Courneya KS, Lubans DR. A systematic review and meta-analysis of social cognitive theory-based physical activity and/or nutrition behavior change interventions for cancer survivors. J Cancer Surviv. 2015;9(2):305-338. doi:10.1 007/s11764-014-0413-z

28. Taylor N, Clay-Williams R, Hogden E, Braithwaite J, Groene O. High performing hospitals: A qualitative systematic review of associated factors and practical strategies for improvement. BMC Health Serv Res. 2015;15(1):1-22. doi:10.1186/s12913-015-0879-Z

29. Thompson D, Baranowski J, Cullen K, Baranowski T. Development of a theory-based internet program promoting maintenance of diet and physical activity change to 8-year-old African American girls.

Computers \& Education. 2007;48(3):446-459. doi:10.1 016/i.compedu.2005.02.005

30. Rinderknecht K, Smith C. Social Cognitive Theory in an After-School Nutrition Intervention for Urban Native American Youth. Journal of Nutrition Education and Behavior. 2004;36(6):298-304. doi:10.1016/s149 9-4046(06)60398-9
31. Hidayanty H, Bardosono S, Khusun H, Damayanti $\mathrm{R}$, Kolopaking S. A social cognitive theory-based programme for eating patterns and sedentary activity among overweight adolescents in Makassar, South Sulawesi: A cluster randomized controlled trial. Asia Pacific Journal of Clinical Nutrition.

2016;25(1):S83-S92. http://apjcn.nhri.org.tw/server/A PJCN/25\%20Suppl\%201/S83.pdf

32. Chapman-Novakofski K, Karduck J. Improvement in knowledge, social cognitive theory variables, and movement through stages of change after a community-based diabetes education program. Journal of the American Dietetic Association. 2005;105(10):1613-1616. doi:10.1016/j.jada.2005.07.0 $\underline{10}$

33. Nematollahi M, Eslami AA. Development and validation of social cognitive theory based questionnaire for physical activity to preventing osteoporosis (PAQ-SCT). Iran J Psychiatry Behav Sci. 2018;12(3). doi:10.5812/ijpbs.12662

34. Walker SN, Sechrist KR, Pender NJ. The healthpromoting lifestyle profile: Development and psychometric characteristics. Nursing Research. 1987;36(2):76-81. doi:10.1097/00006199-19870300 $\underline{0-00002}$

35. Williams DM, Anderson ES, Winett RA. A review of the outcome expectancy construct in physical activity research. Annals of behavioral medicine. 2005;29(1):70-79. doi:10.1207/s15324796abm2901_10

36. Young MD, Plotnikoff RC, Collins CE, Callister R, Morgan PJ. Social cognitive theory and physical activity: A systematic review and meta-analysis. Obes Rev. 2014;15(12):983-995. doi:10.1111/obr.12225

37. Lee CG, Park S, Lee SH, Kim H, Park JW. Social Cognitive Theory and Physical Activity among Korean Male High-School Students. Am J Mens Health. 2018;12(4):973-980. doi:10.1177/1557988318754572

38. Ghoreishi MS, Vahedian-Shahroodi M, Jafari A, Tehranid H. Self-care behaviors in patients with type 2 diabetes: Education intervention base on social cognitive theory. Diabetes \& Metabolic Syndrome. 2019;13(3):2049-2056. doi:10.1016/i.dsx.2019.04.045

39. Anderson ES, Wojcik JR, Winett RA, Williams DM Social-cognitive determinants of physical activity: The influence of social support, self-efficacy, outcome expectations, and self-regulation among participants in a church-based health promotion study. Health Psychology. 2006;25(4):510-520. doi:10.1037/0278-61 33.25.4.510

40. Umstattd M. Self-regulation and Physical Activity: The Relationship in Older Adults. American Journal of Health Behavior. 2008;32(2). doi:10.5993/ajhb.32.2.1 
41. Plotnikoff RC, Lippke S, Courneya KS, Birkett N, Sigal RJ. Physical activity and social cognitive theory: A test in a population sample of adults with type 1 or type 2 diabetes. Applied Psychology. 2008;57:628-643.

42. Mehta P, Sharma M, Bernard A. Social Cognitive Theory as a Predictor of Dietary Behavior and Leisure Time Physical Activity Behavior in Middle-Aged Asian Indian Women Residing in United States. Int $Q$ Community Health Educ. 2010;30(3):257-269. doi:10.2 190/iq.30.3.f

43. Doerksen SE, McAuley E. Social cognitive determinants of dietary behavior change in university employees. Front Public Health. 2014;2:23. doi:10.338 9/fpubh.2014.00023

44. Beverly EA, Fitzgerald S, Sitnikov L, Ganda OP, Caballero AE, Weinger K. Do older adults aged 60-75 years benefit from diabetes behavioral interventions? Diabetes Care. 2013;36(6):1501-1506. doi:10.2337/dc1 $\underline{2-2110}$
45. Rolling TE, Hong MY. The effect of social cognitive theory-based interventions on dietary behavior within children. Journal of Nutritional Health and Food Science. 2016;4(5):1-9. doi:10.15226/jnhfs.2 $\underline{016.00179}$

46. Torkan N, Kazemi A, Paknahad Z, Bahadoran P. Relationship of Social Cognitive Theory Concepts to Dietary Habits of Pregnant Women. Iranian journal of nursing and midwifery research. 2018;23(2):125-130. d oi:10.4103/ijnmr.IJNMR 157_16

47. Anderson-Bill ES, Wientt R, Wojcik J. SelfRegulation, Self-Efficacy, Outcome Expectations, and Social Support: Social Cognitive Theory and Nutrition Behavior. Annals of behavioral medicine: a publication of the Society of Behavioral Medicine. 2007;34:304-312. doi:10.1080/08836610701677659

48. Sheeshka JD, Woolcott DM, Mackinnon NJ. Social Cognitive Theory as a Framework to Explain Intentions to Practice Healthy Eating Behaviors. $J$ Appl Social Pyschol. 1993;23(19):1547-1573. doi:10.11 11/j.1559-1816.1993.tb01047.x 